\title{
Young people's perspectives on farming in Ghana: a Q study
}

\author{
James Sumberg $^{1} \cdot$ Thomas Yeboah $^{2} \cdot$ Justin Flynn $^{1} \cdot$ Nana Akua Anyidoho ${ }^{3}$
}

Received: 24 August 2015 / Accepted: 29 December 2016 / Published online: 13 January 2017

(C) The Author(s) 2017. This article is published with open access at Springerlink.com

\begin{abstract}
An emerging orthodoxy suggests that agriculture is the key to addressing the youth employment challenge in Africa. The analysis that informs this orthodoxy identifies a number of persistent barriers to increased productivity; and the programmes that work to get young people engaged with agriculture make assumptions about the young people's interests and behaviours. In this paper we report results from a study with secondary students in Ghana using Q Methodology. The objective was to determine to what degree the students' perspectives were aligned with the main tenants of the emerging orthodoxy. Results show that different perspectives on the two questions (What explains young people's attitude toward farming? What should be done about young people and farming?) can be identified. There are a number of points of convergence between the students' perspectives and the new orthodoxy. However, two important points of divergence were also identified, and the impications of these are discussed.
\end{abstract}

Keywords Africa · Employment - Agricultural transformation $\cdot$ Rural development

James Sumberg

j.sumberg@ids.ac.uk

1 Institute of Development Studies (IDS), Brighton, UK

2 Centre of Development Studies, Churchill College, University of Cambridge, Cambridge, UK

3 Institute of Statistical, Social and Economic Research, University of Ghana, Legon, Ghana

\section{Introduction}

An emerging orthodoxy among policy makers and development professionals is that the agricultural sector can provide a key to the problem of youth unemployment and underemployment in Africa (Brooks et al. 2012; FAO et al. 2014; MasterCard Foundation 2015; Filmer and Fox 2014). Underpinning this orthodoxy is a belief that agriculture is a sector of both change and opportunity: "the large numbers of young people entering the sector will accelerate the pace of change" (Filmer and Fox 2014, p.137), and in the process young people can shift from job seekers to job creators. An increasing number of development programmes rooted in this orthodoxy place personal attitudes and behaviours at centre stage, including entrepreneurship and an orientation to "farming as a business", and closely articulate these with the new opportunities open to enterprising farmers through, for example, engagement with new markets, value chains, agri-business and information technology.

However there is a disjuncture between the analysis that informs the orthodoxy and the actions that stem from it. On one side of this disjuncture, Brooks et al. (2012) and Filmer and Fox (2014) take a long-term view informed by a recognition of the need to address the existing barriers - many of which are structural - to increased agricultural productivity. Not surprisingly, most of these are the same barriers that have been the focus of agriculture and rural development efforts over decades: lack of research; need for new technology including better crop varieties; need for investment in transportation and infrastructure; need to increase the fluidity of land markets, in particular through rentals, and to address constraints to the intergenerational transfer of land; need to increase access to capital; and a need for schools to do a better job of providing basic skills, and for innovations in agricultural extension. In other words, the goals of raising productivity and creating jobs will require an as yet unseen step change in the "level of investment, 
pace of implementation and quality of programmes" (Filmer and Fox 2014, p.114). On the other side of the disjuncture are the development programmes that commonly include interventions like awareness raising, entrepreneurship and business skills training, the formation of farmer organisations, integration into contract farming models, and promotion of savings and micro-credit. The mismatch between these interventions and the height of the barriers identified by Filmer and Fox is stark.

The available research literature from Africa tends to gravitate toward one of two conclusions: either that many rural young people want to farm but they are constrained by structural factors, and particularly an inability to access land; or that they have little interest in farming, which may reflect, but only in part, a difficulty in accessing land. In Ghana for example, Amanor (2010) argued that young people remained interested in farming, but that processes of commodification limited the availability of family land, which historically young people would have accessed to get themselves started in farming. Rural young people in Burundi aspire to a "farming future", but they felt the need to look elsewhere because of the unsustainability of current practices of land inheritance and farming (Berckmoes and White 2014). In Ethiopia, Bezu and Holden (2014) found that only nine percent of a sample of rural young people planned to pursue agriculture as their livelihood, and linked the pursuit of other livelihood options directly to land scarcity. For Tadele and Gella (2012) working in areas of Ethiopia where land scarcity is a problem, the larger issue is that farming and rural life are seen as "backward, demanding and even demeaning - especially for those who have gone through years of education with higher hopes and expectations" (p.41). This chimes with the findings of a multi-country study (including five sites in four African countries) reported by Leavy and Hossain (2014). These authors conclude that "farming is not a favoured option for the younger generation in rural areas of developing countries, even those in which agriculture remains the mainstay of livelihoods and the rural economy" (p.38). While constraints on access to land and other resources are part of the picture, the turn away from farming is also associated with education and rising aspirations, the low social status of small-scale farming, and the changing nature of employment markets. Petesch and Rodríguez Caillava (2012) report that rural young people who took part in 32 focus group discussions in six African countries were silent or held mixed views about the desirability of farming livelihoods, and also that livelihood aspirations were strongly shaped by gender norms.

Much of the policy discourse around young people, jobs and agriculture in Africa assumes that the challenge is to sensitise, inform and/or convince rural young people that the agricultural sector offers attractive livelihood opportunities. Filmer and Fox (2014) put it succinctly: "Many young people know little of the opportunities and dynamism possible in farming today" (p.117). But given the long list of barriers to increased productivity, and the fact that to date some of these have proven to be intractable, argumentation along this line deserves close attention. In this paper we report the perspectives of students in two high schools in rural Ghana on two closely related research questions: (1) What explains young people's attitude toward farming? and (2) What should be done about rural young people and farming? We submit that the perspectives of young people on these questions are of considerable importance in the light of the attention currently being given to agriculture and youth employment. At what points do the views of young people and policy analysts align or diverge? What evidence is there that young people are misreading the opportunities offered by today's (or tomorrow's) agriculture? A systematic understanding of young people's perspectives should help to avoid policy implementation failure caused by poor alignment between the views of policy makers on the one hand and of young people on the other.

\section{Methodology}

\section{General overview of Q Methodology}

This study used Q Methodology (Q) which is used to systematically explore and analyse different perspectives (subjectivities or viewpoints) on a particular question or issue (Watts and Stenner 2012). Baker (2006) suggests that $Q$ is appropriate when the aim is to explore questions about personal experience and matters of taste, values and beliefs. Q combines qualitative and quantitative analysis. Data is collected in the form of a Q-sort, which requires a participant to sort a number of statements about a particular question according to a subjective dimension such as "most agree" to "most disagree". The sorting patterns of a group of individual Q-sorts are then intercorrelated and compared and contrasted using factor analysis. This allows for any "shared modes of engagement, orientations or forms of understanding to be detected" (Stenner et al. 2000, p.442). The value of Q compared to, for example, survey methods is that it provides a systematic means of identifying and exploring the different perspectives about a question that are represented within a selected group of participants. Q has been used to address a wide variety of research questions and issues, and Previte et al. (2007) argued that $\mathrm{Q}$ offers particular synergies and opportunities for rural social science. In work related to that reported here we used Q in Ghana to explore rural high school students' perspectives on the questions: What is a desirable job? and What makes a job desirable? (Yeboah et al. 2016).

Q has been critiqued for being subjective and too dependent on the individual researcher's interpretation, but it is now widely accepted as providing valuable insights into participants' views and perspectives (Cross 2005; Brown 1997). 


\section{Q-set design and content}

A Q-set is a collection of statements about a particular research question that comes close to capturing the full gamut of potential views on that question. The statements in a Q-set are sorted by individual study participants according to a particular condition of instruction (e.g. "Question: What explains young people's attitude toward farming? Condition of Instruction: Use this grid to sort these 16 statements from Most Disagree to Most Agree").

Different approaches to the development of a Q-set are recognised (Watts and Stenner 2012). For this research a separate Q-set was developed for each of the two research questions based on our previous research on and interactions with rural young people, other rural residents and development professionals in Ghana and elsewhere in Africa; our reading of the relevant academic and policy literature; and our understanding of relevant policy debates. ${ }^{1}$ The Q-set for research question 1 - "What explains young people's attitude toward farming?" - was structured such that the statements fell roughly into four categories, with young people's attitude toward farming potentially explained with reference to: young people themselves, farming and farmers, rural areas and/or access to resources. The research question was formulated in a way that neither specified nor made assumptions about young people's attitude toward farming. Individual statements could be interpreted as highlighting either a positive or negative aspect of farming, although the Q-set was not balanced in this regard as it was difficult to identify potentially positive aspects of smallholder farming as it exists today.

The Q-set for research question 2 - "What should be done about rural young people and farming?" - contained statements that referred to education and training, changes to the education system, the modernisation of agriculture, the provision of more services in rural areas, and what might be thought of as institutional change that would, for example, give young people more of a voice in local affairs or increase their access to resources such as land.

There are no specific rules about the number of statements that should be included in a Q-set, however, many Q studies use Q-sets containing between 40 and 60 statements (Watts and Stenner 2012). Thus a Q-set with only 16 statements is at the low end of accepted practice. We note however that Watts and Stenner (2012) recognise that "in some circumstances, it can even be sensible to employ a more limited number of items" (p.61); they suggest that such circumstances might include when participants are children or when participants are asked to complete multiple Q-sorts in a single sitting. In our study both of these circumstances applied.

\footnotetext{
${ }^{1}$ The authors have between them more than 40 years of rural research in West Africa, including work on rural young people and agriculture in Ghana.
}

\section{Participants}

For this study we worked with high school students (aged 15-23) attending Tepa Senior High School in Ashanti Region and Savelugu Senior High School in Northern Region. These schools were selected because they are located within contrasting farming regions. Tepa is in Ghana's cocoa producing area where good annual rainfall and a long growing season support a variety of crop production activities. Rainfall around Savelugu is lower than in Tepa, and limits crop production options and outcomes. The area around Savelugu would generally be considered to have lower agricultural potential than Tepa, and poverty indicators in Northern Region are higher than in Ashanti Region (Al-Hassan and Diao 2007; Ghana Statistical Service 2014).

Q Methodology is not concerned with representative samples or with large sample sizes: our aim was to work with a group of students that included the diversity present in the schools, particularly in terms of age and gender. We worked with officials at the two schools to identify students who were willing to participate in the study. An element of self-selection was therefore inevitable.

After an introduction to the study the participant was given a shuffled pack of cards with each card containing a single statement. They were instructed to read and consider each card in turn, relative to the research question, and to sort the cards into three piles: those they agreed with; those they did not agree with; and those they were ambivalent about, did not have strong feelings about or did not understand. Those they did not understand were clarified before proceeding. Next they were instructed to take each pile of cards in turn and place each card on a symmetrical grid based on the strength of their agreement with the content. In principle the completed sorting exercise reveals the participant's subjective view on the research question. An example of a completed sort is shown in Fig. 1. After each sorting exercise participants were asked if they had any comments they wanted to make about the ranking they had just completed. Notes were taken and these were used to inform the respective factor interpretations.

Across the two sites we worked with 38 individuals (Table 1). Each participant completed two sorts, one for each research question. What follows is thus the analysis of two separate Q studies.

\section{Analysis}

Each of the studies was analysed separately using the software PQMethod $^{2}$ (Schmolck 2014). First, statements and participants' sort data were entered using PQMethod. The sort patterns of the participants in each study were then intercorrelated. The resulting

\footnotetext{
${ }^{2}$ PQMethod is a freely available statistical program tailored to the requirements of Q studies. See: http://schmolck.userweb.mwn. de/qmethod/\#PQMethod
} 
Fig. 1 A completed Q-sort

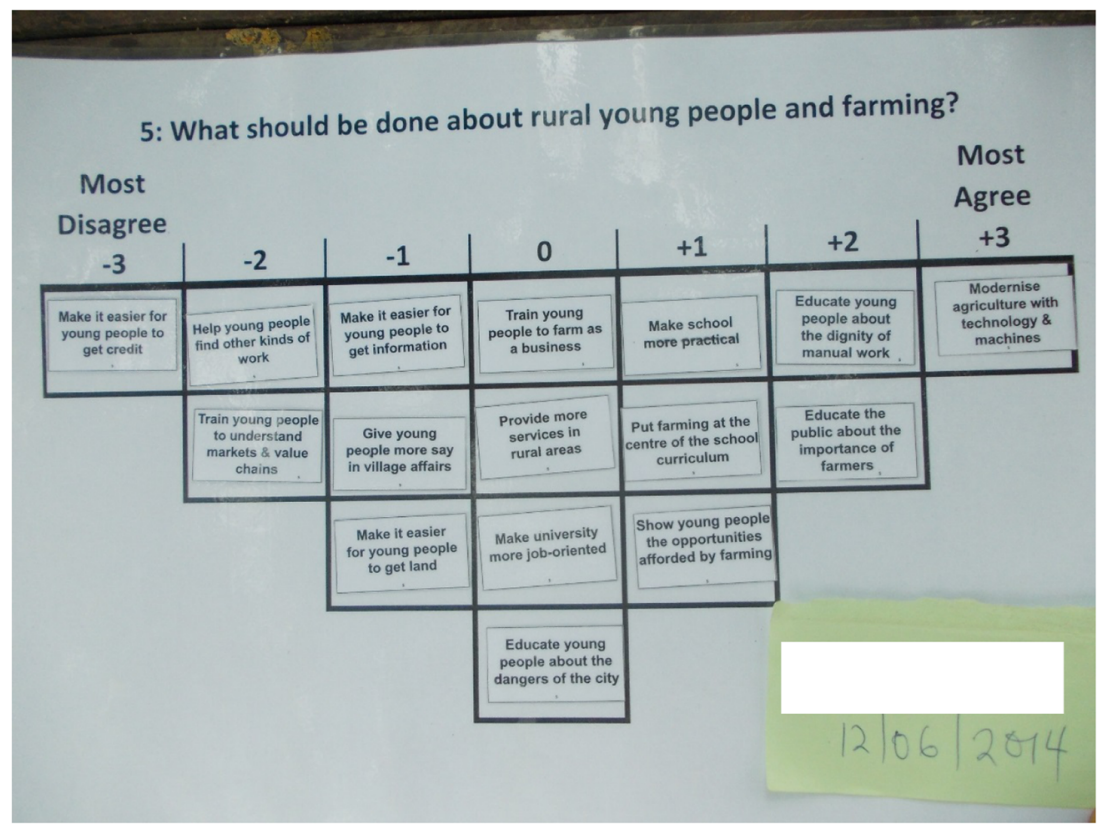

correlation matrix provided the basis for the extraction of factors - i.e. common sort patterns across a number of participants. For this study we used the Principle Component Analysis module (QPCA) of PQMethod to extract factors. Factors were rotated using the Varimax module (QVARIMAX). A number of different factor solutions were generated and explored. The solutions presented here for research questions 1 and 2 both retained four factors. All of these factors had two or more significant factor loadings following extraction, and for all factors the crossproduct of the two highest loadings exceeded the standard error. Finally, the retained factors are not highly correlated, suggesting that the factors do represent different viewpoints (Tables 2 and 3).

For each factor that was identified, the Q-sorts of two or more individuals who unambiguously loaded highly on the factor, as determined by the factor (loading) matrix, were selected and used as the "defining sorts" for that factor. The weighted average of these defining sorts was used to produce a factor array that exemplified the factor. For example, a factor array for the question "What explains young people's attitude toward farming?" took the form of a list of all of the statements associated with this question, with each statement having a weighted average Zscore (or factor score). The Z-score factor array can then be converted to a factor array of Q-sort values (i.e. ranging from -3 (most disagree) to +3 (most agree) (Schmolck 2014; Watts

Table 1 Study participants

\begin{tabular}{llll}
\hline Location & \multicolumn{2}{l}{ Participants (number) } \\
\cline { 2 - 4 } & Males & Females & Total \\
\hline Tepa & 11 & 9 & 20 \\
Savelugu & 7 & 11 & 18 \\
Total & 18 & 20 & 38 \\
\hline
\end{tabular}

and Stenner 2012). Factor arrays of Q-sort values for research questions 1 and 2 are shown in Tables 4 and 5 respectively, and these arrays provided some of the raw material for factor interpretation. To systematise the interpretation process we used the "crib sheet" method described by Watts and Stenner (2012). In essence, the process of factor interpretation "involves the production of a series of summarizing accounts, each of which explicates the viewpoint being expressed by a particular factor. These accounts are constructed by careful reference to the positioning and overall configuration of the items in the relevant $[. .$.$] factor$ arrays" (Watts and Stenner 2005, p.82). For the interpretation of each factor the crib sheet facilitates this process by placing statements into five groups: those with Q-sort values of +3 or +2 ; those with Q-sort values that are higher than in any other factor; those with Q-sort values that are lower than in any other factor; those with Q-sort values that are the same as in any other factor; and those with Q-sort values of -3 or -2 .

For clarity, in the remainder of this paper we substitute the word perspective for factor.

An important limitation of this study is that all of the students who participated were enrolled in senior high school. It follows that the perspectives of young people who for

Table 2 Factor correlation matrix for research question 1

\begin{tabular}{|c|c|c|c|c|}
\hline \multirow[t]{2}{*}{ Factor } & \multicolumn{4}{|c|}{ Factor } \\
\hline & 1 & 2 & 3 & 4 \\
\hline 1 & 1.0 & 0.0027 & -0.2206 & 0.0054 \\
\hline 2 & & 1.0 & 0.2384 & 0.1324 \\
\hline 3 & & & 1.0 & -0.1497 \\
\hline 4 & & & & 1.0 \\
\hline
\end{tabular}


Table 3 Factor correlation matrix for research question 2

\begin{tabular}{|c|c|c|c|c|}
\hline \multirow[t]{2}{*}{ Factor } & \multicolumn{4}{|c|}{ Factor } \\
\hline & 1 & 2 & 3 & 4 \\
\hline 1 & 1.0 & 0.2066 & 0.3073 & 0.0634 \\
\hline 2 & & 1.0 & 0.1114 & -0.1042 \\
\hline 3 & & & 1.0 & 0.2707 \\
\hline 4 & & & & 1.0 \\
\hline
\end{tabular}

whatever reason are not in senior high school will not necessarily be represented in the interpretations presented in the next section. In 2014/15, there were 804,974 students enrolled in 863 senior high schools in Ghana, with an estimated gross enrolment rate of estimated to be 45.8\% (EMIS 2015). Another limitation is that we have only limited information about the family or socio-economic circumstances of the students who participated in the study.

\section{Results}

\section{Research question 1: What explains young people's attitude toward farming?}

Four perspectives on this question were identified. The interpretations of these are presented in turn below.

Table 4 Statements and factor arrays for research question 1 (What explains young people's attitude toward farming?)

\begin{tabular}{llllll}
\hline \multirow{2}{*}{ Statement } & \multicolumn{3}{l}{ Perspective } \\
\cline { 2 - 5 } & 1 & 2 & 3 & 4 \\
\hline Young people want modern jobs & 3 & 2 & 1 & 1 \\
Young people don't like hard work & 2 & -1 & 2 & -1 \\
Young people have more education than their parents & 2 & -1 & -1 & -2 \\
Rural areas lack schools, clinics \& entertainment & 1 & 1 & 0 & 3 \\
Young people want the "bright lights" of the city & 1 & 0 & 1 & 1 \\
There are many other work options & 1 & -1 & 0 & 2 \\
Farmers are their own boss & 0 & 0 & -3 & 0 \\
Young people cannot get land & 0 & 0 & 0 & -1 \\
Farmers always have food to eat & 0 & 2 & -2 & 1 \\
Parents encourage children to leave farming & 0 & 1 & -1 & -3 \\
Young people are not taken seriously in villages & -1 & -2 & -1 & 0 \\
Leaving the village is part of growing up & -1 & -3 & -2 & 0 \\
Young people have unrealistic dreams & -1 & -2 & 0 & 0 \\
Farmers are not respected & -2 & 3 & 2 & -2 \\
Farmers are poor & -2 & 0 & 1 & -1 \\
Farmers work hard for little reward & -3 & 1 & 3 & 2
\end{tabular}

Perspective 1: "It's all about us young people" From this perspective the explanation of young people's attitude toward farming is more to do with young people's sense of themselves than anything particular about farming. They want modern jobs; have more education than their parents (this is a distinguishing statement for this perspective); and don't like hard work. The self-centredness and confidence that underpin this perspective come through in the young people's sense that there are many other options for work and a downplaying of the idea that young people's dreams about their futures may be unrealistic.

In contrast, the oft-cited conditions of small-scale farmers not being respected, being poor, and working hard for little reward - are heavily discounted as explanations. Indeed among the four perspectives, this one most strongly disagrees with the statements that farmers are poor and that they work hard for little reward (both of which are distinguishing statements for this perspective). It is not the associated poverty that makes farming undesirable, but the idea that farming is not modern and thus not compatible with their educational achievements. As a 20-year old female in Tepa, whose father is a teacher, put it: "Young people think farming is a dirty work so they want to be in the city for modern jobs" (Participant 20, Tepa).

As in some of the other perspectives, locational issues, including both the attraction of urban areas and the lack of services in rural areas, provide part of the explanation of young people's attitude toward farming. On the other hand, the propositions that young people are not taken seriously in the village environment and that leaving the village (and thus rejecting farming at least temporarily) is simply part of growing-up are not important to this perspective.

Given the strong internal orientation of this perspective it is not surprising that there is neither agreement or disagreement with what might be considered two positive aspects of farming - being your own boss and always having food to eat. Like the other perspectives, this one neither agrees nor disagrees with the proposition that young people's attitude toward farming is explained by their inability to access land.

Perspective 2: "Farmers are not respected" From this perspective, at the heart of young people's attitude toward farming is the tension between the lack of respect given to farmers on the one hand, and young people's interest in modern jobs on the other. A 19-year old male from Tepa, whose father is a surveyor, put it succinctly: "I have observed that farmers are not respected and regarded and that is why young people don't want to farm" (Participant 9, Tepa). There is however some ambiguity in the underlying attitude toward farming: while it is not a distinguishing statement, in this perspective farmers always having food to eat is ranked at +2 , higher than any other perspective. While farmers may work hard for little reward, this perspective neither agrees nor disagrees that their poverty helps explain young people's attitude. 
Table 5 Statements and factor arrays for research question 2 (What should be done about rural young people and farming?)

\begin{tabular}{|c|c|c|c|c|}
\hline \multirow[t]{2}{*}{ Statement } & \multicolumn{4}{|c|}{ Perspective } \\
\hline & 1 & 2 & 3 & 4 \\
\hline Educate the public about the importance of farmers & 3 & 1 & 0 & 2 \\
\hline Modernise agriculture with technology \& machines & 2 & 3 & 2 & 1 \\
\hline Train young people to farm as a business & 2 & 1 & 1 & 0 \\
\hline Show young people the opportunities afforded by farming & 1 & 2 & 0 & -2 \\
\hline Put farming at the centre of the school curriculum & 1 & 0 & -3 & -2 \\
\hline Provide more services in rural areas & 1 & -1 & 1 & 0 \\
\hline Give young people more say in village affairs & 0 & -2 & -1 & -3 \\
\hline Educate young people about the dignity of manual work & 0 & 0 & 2 & -1 \\
\hline Make university more job-oriented & 0 & -3 & 0 & 1 \\
\hline Train young people to understand markets \& value chains & 0 & 0 & 1 & -1 \\
\hline Help young people find other kinds of work & -1 & -2 & -1 & 3 \\
\hline Make it easier for young people to get information & -1 & -1 & -2 & 0 \\
\hline Make school more practical & -1 & -1 & -1 & 2 \\
\hline Educate young people about the dangers of the city & -2 & 0 & 3 & 1 \\
\hline Make it easier for young people to get land & -2 & 1 & 0 & 0 \\
\hline Make it easier for young people to get credit & -3 & 2 & -2 & -1 \\
\hline
\end{tabular}

The young people associated with this perspective agree that encouragement by parents to leave farming helps explain young people's attitude. In the words of another 19-year old male from Tepa, "Most parents think farming is a low class job" (Participant 2, Tepa). They also agree that the lack of services and facilities in rural areas explains in part young people's attitude toward farming. Two potential pull factors - the bright lights of the city and the idea that there are many work options other than farming - figure less prominently in this perspective than in the others.

While the role of encouragement from parents is recognised, this perspective strongly disagrees with the proposition that young people's attitude toward farming is explained by the idea that leaving the village is part of growing up, or because young people are not being taken seriously in village environments (both of these are distinguishing statements for this perspective). Again, as with the other perspectives, there is neither agreement nor disagreement that young people's attitude toward farming is explained by their inability to access land.

Perspective 3: "Farming is the problem" In contrast to Perspective 1, where the explanation for young people's attitude toward farming is rooted first and foremost in their sense of themselves, Perspective 3 more explicitly references the negative conditions associated with farming. Indeed, of the four perspectives, this one stresses most strongly the negatives associated with farming (and disagrees most strongly with the statements about farmers always having food to eat and being their own boss - both distinguishing statements for this perspective). Thus, young people associated with this perspective agree that attitudes toward farming are explained by farmers working hard for little reward, not being respected, and being poor. These negative aspects of farming are in tension with the young people's dislike for hard work and attraction to the city and modern jobs (although in this perspective, agreement with the explanatory statement that young people want modern jobs is less strong $(+1)$ than in Perspective $1(+3)$ ).

Young people associated with this perspective neither agree nor disagree that the lack of services in rural areas (a distinguishing statement for this perspective) or the existence of many other work options explain attitudes toward farming. In contrast to Perspective 1 , here there is some sense that if farming provided a better livelihood and more social status, young people's attitude toward it might be more positive. This sense also reflects the fact that the perspective puts little explanatory weight on the other push factors like restricted access to land, parental encouragement or a social expectation to leave the village.

Perspective 4: "Rural areas are not attractive and there are other options" This perspective, more than any other, highlights the lack of services and facilities in rural areas in explaining young people's attitude toward farming (this is a distinguishing statement for this perspective). A 15-year old female from Savelugu suggested that the reason young people leave rural areas in the first place is the lack of schools, and that this also signals a break with farming (Participant 1, Savelugu). The limitations of rural areas form the backdrop for a mismatch between the hard work and limited rewards of farming on the one hand, and young people's sense that there are other opportunities for work (a distinguishing statement), and their attraction to modern jobs and urban environments on 
the other. An 18-year old male from Tepa put it this way: “... there are many jobs for young people, so they do not want to go into farming with cutlasses" (Participant 3, Tepa). Smallscale, dirty, low technology farming - "farming with cutlasses" - is being portrayed here as the antithesis of modern work, and thus less desirable than any of the "many jobs" that are available.

While this perspective suggests a largely negative attitude toward farming, neither farmers' poverty nor lack of respect figure prominently in the explanation of young people's attitude. It is also worth noting that in contrast to Perspective 1, here the young people disagree with the idea that attitudes toward farming are explained by the fact that young people have more education than their parents (a distinguishing statement). This perspective does not ascribe any explanatory weight to other possible push factors, e.g. that young people cannot access land, don't like hard work or are encouraged to leave farming by their parents (at -3 , this is a distinguishing statement for this perspective).

\section{Research question 2: What should be done about rural young people and farming?}

Four perspectives were identified, and modernisation of farming figures centrally in three of them. The interpretations of these perspectives are presented in turn below.

Perspective 1: "Increase public awareness, and modernise" From this perspective the most important thing to do about young people and farming is to change the public mood music around farmers and farming. Greater public awareness of the importance of farming (a distinguishing statement) might give farming more status and increase the self-esteem of farmers, and thus make farming more attractive to young people. According to an 18-year old female from Tepa, "Farmers are not respected in society compared to jobs like medical doctor $[\ldots]$ the public need to be educated to orient young people and others to go into farm" (Participant 13, Tepa). But from this perspective a change in public perception is just the start. The material reality of farming also needs to change through modernisation and the introduction of technology and machines - and rural areas made more attractive through better service provision. Finally, young people need to be sensitised to the opportunities offered by farming, and trained to take advantage of them by approaching farming as a business (a distinguishing statement).

While sensitisation and training are important in this perspective, there is no suggestion that young people's deeper attitudes about hard work or life in the city need to be addressed. Nor is there is any sense that young people's access to information, land or credit are issues. Indeed, this perspective is less concerned with access to credit or land (a distinguishing statement) than any of the others.
Perspective 2: "Modernise, open their eyes and increase access" From this perspective, modernisation is the key to what should be done about young people and farming. A 16-year old female from Savelugu made this clear: "Providing technology and machines will raise the interest of young people to go into agriculture" (Participant 15, Savelugu). However, modernisation will not be enough: it should be accompanied by sensitisation in relation to the opportunities afforded by farming (a distinguishing statement), and easier access to both credit and land (also distinguishing statements). Improved access to these resources will allow young people to take advantage of the opportunities afforded by farming. This perspective is clearer about the need for improved access to credit and land than any other (although a 23-year old male from Savelugu warned that if available, credit would not necessarily be used for farming). Public education about the importance of farmers has some role to play, but this is less of a priority than in Perspectives 1 and 4 .

There is neither agreement nor disagreement that young people's attitude toward hard work or their misconceptions of life in the city (a distinguishing statement) need to be addressed, and there is some disagreement with the idea that a lack of services or facilities in rural areas is an important problem (a distinguishing statement). In contrast, young people associated with this perspective strongly disagreed with the statement that university should be more job-oriented and that young people should be helped to find other kinds of work (both distinguishing statements).

Perspective 3: "Reorient the young people, and modernise" From this perspective, much of what needs to be done about young people and farming is focused on the young people themselves. Specifically they need to be educated about both the dangers of the city and the dignity of manual work (both are distinguishing statements). Three of the four participants whose sorts weighed heavily on this perspective were from Tepa, the site with the higher agricultural potential. This sense that young people need to be both protected and also reoriented is evident only in this perspective. It can also be seen to mirror Perspective 1 ("It's all about us young people") on the first research question.

But there is more that needs to be done, and specifically the combination of modernising agriculture and training young people to understand market-based opportunities (distinguishing statement), and to approach them in a business-like manner. As with Perspective 1, there is some sense that more services need to be provided to rural areas.

Young people associated with this perspective strongly disagree that a response should be to put farming at the 
centre of the school curriculum or to make access to land and credit easier. Indeed, easier access to credit was seen as a corrupting influence by an 18-year old male from Tepa who suggested that with credit, young people will "always work for profit and not for the nation" (Participant 3, Tepa). The idea that working for personal profit is in tension with working for the good of the nation reflects our finding that among this same group of young people there was a strong sense of wanting to make a positive contribution to community and nation (Yeboah et al. 2016).

Perspective 4: "Help them get out" In contrast to all the others, this perspective suggests that the most important thing that should be done about young people and agriculture is to help them find other kinds of work (distinguishing statement). All key sorters for this perspective were from Savelugu, the site with the lower agricultural potential. Part of expanding their employment options is to make school more practical (distinguishing statement) and university more job-oriented. But expanding work options also pose challenges, and from this perspective young people should be educated about the dangers of the city. Farming is not completely out of the picture, as educating the public about the importance of farming and the need for agricultural modernisation are also given some weight. However, reflecting strong agreement that young people should be helped to find other work, there is no agreement that easier access to land, credit or information should be prioritised. Nor is there agreement that young people need training in market or business-oriented farming, or a change in their attitude in relation to manual work.

\section{Discussion}

The previous section showed that different perspectives on the two questions can be identified amongst the participating secondary school students. In relation to the Question 1 (What explains young people's attitude toward farming?), "It's all about us young people" (P1) has a strong inward orientation, explaining young people's attitude toward farming with reference to their education, desire for modern jobs, optimistic sense of the employment opportunities available to them, and their wish to avoid "hard work". This is in marked contrast to the "Farmers are not respected" (P2) and "Farming is the problem" (P3) perspectives, which explain young people's attitudes largely in terms of the negatives associated with farming (lack of respect, poverty, and hard work). P4 puts the lack of services and facilities in rural areas at centre stage, and combines this with optimism about alternative employment opportunities. Overall, these perspectives suggest first, that young people have a largely negative attitude toward farming, and second, that this negativity is rooted in quite different perceptions and understandings. This points to the possibility of a more targeted approach to policy and programmes that seek to address rural employment through the agricultural sector. There may be, for example, little to be gained by trying to engage with young people who share the "It's all about us young people" perspective. On the other hand, if the negatives associated with farming - including drudgery, low financial returns and lack of respect - can be addressed, then successful engagement with young people who share P2 and P3 may well be possible.

Perhaps not surprisingly, the perpectives on Question 2 (What should be done about young people and farming?), mirror to a great degree those identified for Question 1 . Thus, while three perspectives highlight the importance of agricultural modernisation, $\mathrm{P} 1$ prioritises increased public awareness of the importance of farmers (addressing the problem of lack of respect); $\mathrm{P} 2$ combines modernisation with training and improved access to resources; and $\mathrm{P} 3$ prioritises the reorientation of young people's attitudes toward urban life and manual work. The perspective "Help them get out" (P4) is distinct in that its main thrust is to assist young people to find work that is not associated with farming.

As indicated earlier, policy and programmes generally assume that agriculture currently offers, or in the near future will offer, attractive income generation and employment opportunities. The challenge that they set themselves is to bring these opportunities to the attention of young people and provide the skills - both entrepreneurial and technical - needed to take advantage of them. This assumption and programming approach persists despite the plethora of barriers to increased productivity, the sine qua non for the generation of quality employment in the agriculture sector, that have been identified. Most of these barriers are long-standing, and several are deeply structural.

A number of aspects of some of the perspectives articulated by the students align with elements of the new orthodoxy around young people, employment and agriculture. For example, the need to modernise agriculture with new technology and mechanisation features in three perspectives on Question 2, including the dominant one, "Increase public awareness, and modernise" (P1). To varying degrees, $\mathrm{P} 1, \mathrm{P} 2$ and $\mathrm{P} 3$ are also in agreement with the view that young people should be helped to see the opportunities offered by agriculture and trained to farm in a more business-like manner.

However our results indicate that the orthodoxy and the students' perspectives diverge at two important points. First, while the orthodoxy has much to say about the state of African agriculture and how it must change, other than the need for awareness raising and skills enhancement, it is nearly silent on the young people themselves. In other 
words, it seems to assume that if farming's problems can be fixed, and young people trained, they will be content to work in agriculture. This assumption might hold for the students associated with the perspectives "Farmers are not respected" (P2) and "Farming is the problem" (P3) on Question 1. However, it is unlikely to hold for students associated with the dominant perspective on this question, "It's all about us young people" (P1). This perspective suggests that the students' sense of their educational advantages, desire for modern jobs, dislike of hard work and the lack of services in rural areas may well put them beyond reach. Again the need for more nuanced and targeted policy and programmes is clearly indicated.

Another important point of divergence is around land. In line with some research evidence, including findings from Ghana (e.g. Amanor 2010), the orthodoxy suggests that an inability to access land is an important barrier for young people who want to start farming independently. Hence, the call for more fluidity in land markets. However, in explaining the attitude of young people toward farming, none of the four perspectives showed any level of agreement with the statement "Young people cannot get land" (Table 2). Further, in relation to what should be done about young people and farming, only one perspective, "Modernise, train and increase access" (P2), showed any positive agreement with the statement "Make it easier for young people to get land" (Table 3). This perspective is also the only one to suggest that steps should be taken to make it easier for young people to access credit. Are the students too inexperienced or too far removed from rural realities to understand the difficulties of accessing land? Do these young people come from privileged families for whom access to land is unproblematic? Or, alternatively, are they reflecting their awareness of the multiple options, channels and arrangements, including borrowing and renting, through which young people can access land (e.g. Okali and Sumberg 2012)?

\section{Conclusion}

The rationale for our interest in the perspectives of young people was based on the proposition that policy and programmes addressing employment of young people in rural areas will have a higher probability of success if they align with the young people's views of both the problem and how it can be addressed. We are not, however, suggesting that policy can or should be read directly from any of these perspectives.

Our results demonstrate that different explanations about young people's attitude to farming and what should be done about it can be identified, even among a relatively circumscribed group of secondary school students. There is little indication that the gender of the students or the agricultural potential of the areas in which the schools are located are driving these prespectives. The one exception to this is that all the key sorters associated with P4 ("Help them get out") on Question 2 (What should be done about young people and farming?) were from the school located in the area with lower agricultural potential.

There are a number of points of convergence between the students' perspectives and the new orthodoxy on youth employment and agriculture. However, two important points of divergence were also identified: the dominant perspective on Question 1 provides little encouragement that even with awareness raising and training the students would be interested in employment in farming; and the students did not consider restricted access to land to explain young people's atitude toward farming or as an important constraint to be adressed.

We do not know if the perspectives we have identified are in line with the views of secondary school in Ghana more broadly, or with other groups of young people, particularly those who have not continued into secondary school. This certainly deserves further research. However if they are aligned, our findings raise important concerns about the new orthodoxy. At the very least, better disaggregation and targeting are called for. But perhaps more importantly, the disjuncture identified in the introduction to this paper - between on the one hand the difficulty and time required to address existing barriers to increased productivity, and on the other, the common suite on youth-focused interventions - must be acknowledged and addressed more honestly and explicitly. The challenge is not so much how to get young people interested in agriculture, but how to make agriculture worthy of their attention. Unfortunately the history of much agricultural development in Ghana, and Africa more broadly, does not engender confidence in the ability of policy and programmes to effectively support the rapid modernisation of small-scale agriculture. As long as this remains the case, it is very short-sighted to think that agriculture can provide the employment sweet spot for young rural Africans.

Acknowledgement The authors acknowledge the very helpful comments of three anonymous reviewers.

\section{Compliance with ethical standards}

Funding This research was funded partly by a grant to IDS from Irish Aid, and partly by UKAID of the UK Government through a grant to the Future Agricultures Consortium (project 200456).

Conflict of interest The authors declare that they have no conflict of interest. 
Open Access This article is distributed under the terms of the Creative Commons Attribution 4.0 International License (http:// creativecommons.org/licenses/by/4.0/), which permits unrestricted use, distribution, and reproduction in any medium, provided you give appropriate credit to the original author(s) and the source, provide a link to the Creative Commons license, and indicate if changes were made.

\section{References}

Al-Hassan, R. M., \& Diao, X. (2007). Regional Disparities in Ghana: Policy Options and Public Investment Implications. IFPRI Discussion Paper 693 Accra: IFPRI.

Amanor, K. S. (2010). Family values, land sales and agricultural commodification in south-eastern Ghana. [Article]. Africa, 80(1), 104 125. doi:10.3366/e0001972009001284.

Baker, R. M. (2006). Economic rationality and health and lifestyle choices for people with diabetes. Social Science and Medicine, 63(9), 2341-2353.

Berckmoes, L., \& White, B. (2014). Youth, farming and precarity in rural Burundi. European Journal of Development Research, 26(2), 190 203. doi:10.1057/ejdr.2013.53.

Bezu, S., \& Holden, S. (2014). Are rural youth in Ethiopia abandoning agriculture? World Development, 64, 259-272. doi:10.1016/j. worlddev.2014.06.013.

Brooks, K., Zorya, S., \& Gautam, A. (2012). Employment in agriculture: Jobs for Africa's youth. In 2012 global food policy report. Washington DC: IFPRI.

Brown, S. R. (1997). The history and principles of $Q$ methodology in psychology and the social sciences. Kent, $\mathrm{OH}$ : Department of Political Science, Kent State University.

Cross, R. M. (2005). Exploring attitudes: the case for Q methodology. Health Education Research, 20(2), 206-213.

EMIS. (2015). Report on basic statistics and planning parameters for senior high schools in Ghana 2014/2015. Republic of Ghana: Accra Ministry of Education.

FAO, CTA, \& IFAD (2014). Youth and agriculture: key challenges and concrete solutions. Rome: FAO in collaboration with CTA and IFAD.

Filmer, D., \& Fox, L. (2014). Youth employment in Sub-Saharan Africa (Africa development series). Washington, DC: World Bank.

Foundation, M. C. (2015). Youth at work: Building economic opportunities for young people in Africa. Toronto: MasterCard Foundation.

Ghana Statistical Service. (2014). Ghana living standard survey 6: poverty profile report. Accra: Government of Ghana.

Leavy, J., \& Hossain, N. (2014). Who wants to farm? youth aspirations, opportunities and rising food prices IDS working paper 439. Brighton: Institute of Development Studies.

Okali, C., \& Sumberg, J. (2012). Quick money and power: tomatoes and livelihood building in rural brong ahafo, Ghana. IDS Bulletin, 43(6), 44-57. doi:10.1111/j.1759-5436.2012.00378.x.

Petesch, P., \& Rodríguez Caillava, I. (2012). Voices of young villagers in SubSaharan Africa. Background paper. Washington, DC: World Bank.

Previte, J., Pini, B., \& Haslam-McKenzie, F. (2007). Q methodology and rural research. Sociologia Ruralis, 47(2), 135-147. doi:10.1111/j.1467-9523.2007.00433.x.
Schmolck, P. (2014). PQMethod Manual (version 2.35). Available at: http://schmolck.userweb.mwn.de/qmethod/pqmanual.htm. Accessed July 72016.

Stenner, P., Dancey, C., \& Watts, S. (2000). The understanding of their illness amongst people with irritable bowel syndrome: a Q methodological study. Social Science and Medicine, 51, 439-452.

Tadele, G., \& Gella, A. A. (2012). 'A last resort and often Not an option at All': farming and young people in Ethiopia. IDS Bulletin, 43(6), 33-34.

Watts, S., \& Stenner, P. (2005). Doing Q methodology: theory, method and interpretation. Qualitative Research in Psychology, 2, 67-91.

Watts, S., \& Stenner, P. (2012). Doing $Q$ methodological research: Theory, method and interpretation. London: Sage.

Yeboah, T., Sumberg, J., Flynn, J., \& Anyidoho, N. A. (2016). What is a desirable job? what makes a job desirable? findings from a Q study with students and parents in rural Ghana. European Journal of Development Research. doi:10.1057/s41287-016-0006-y.

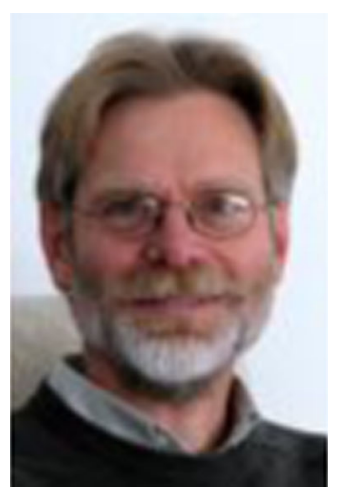

James Sumberg is a Research Fellow at the Institute of Development Studies (IDS) and leads the Rural Futures research cluster.

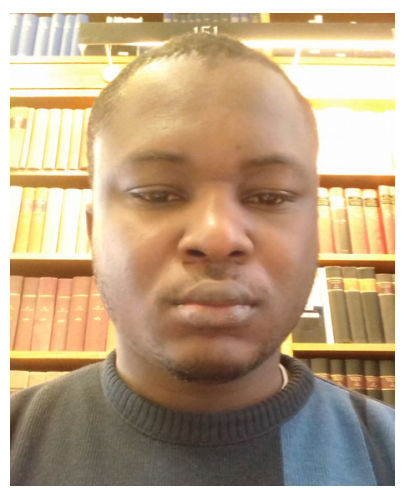

Thomas Yaboah is a $\mathrm{PhD}$ candidate Centre of Development Studies, Churchill College, University of Cambridge. 


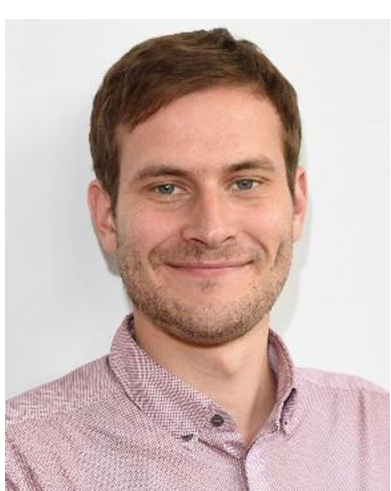

Justin Flynn is a Research Officer at the Institute of Development Studies (IDS). He is currently working on young people's involvement in savings and credit associations in Africa.

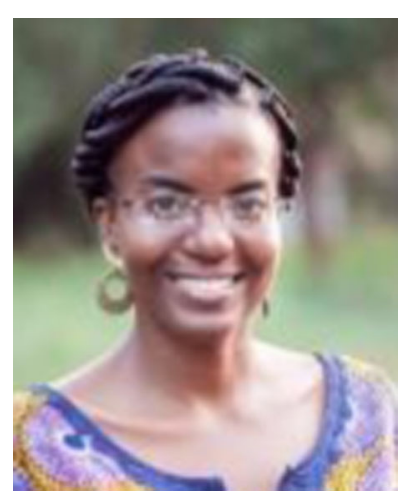

Nana Akua Anyidoho is a

Senior Research fellow at the Institute of Statistical, Social and

Economic Research, University of Ghana, Legon. 